\title{
Effect of dopamine infusion on gastric and pancreatic secretion and on gastrin release in man
}

\author{
R. CALDARA ${ }^{1}$, C. FERRARI, M. ROMUSSI, L. BIERTI, S. GANDINI, AND \\ G. CURTARELLI \\ From the Second Department of Medicine and Department of Nuclear Medicine, Fatebenefratelli Hospital, \\ and Third Medical Clinic, University of Milan, Milan, Italy
}

SUMMARY The effect of dopamine infusion on basal and pentagastrin-stimulated gastric secretion, on basal and secretin-CCK-PZ-stimulated pancreatic secretion, and on basal and meal-induced gastrin release has been evaluated in healthy volunteers. Both basal and stimulated gastric acid secretion were significantly inhibited during dopamine infusion with a significant rebound to preinfusion values after discontinuing dopamine. These effects were prevented by pretreatment with the antidopaminergic drug, metoclopramide. A slight but not significant decrease in amylase and bicarbonate outputs was also observed during dopamine infusion, while gastrin release did not change. These data suggest the existence of dopaminergic mechanisms in the regulation of gastric acid secretion in man.

The role of dopamine as a neurotransmitter in the central nervous system has been known for several years. Dopaminergic neurons have been identified in various structures including the basal ganglia, the medulla oblongata, and the hypothalamus, where they prevent symptoms of Parkinsonism, produce nausea and vomiting, and suppress prolactin secretion (see Thorner, 1975, for review). In recent years, it has become increasingly evident that dopamine acts as a neurotransmitter in the peripheral nervous system also. Significant amounts of this amine have been found in the sympathetic ganglia and nerves and in several tissues throughout the body (Thorner, 1975). Specific dopamine receptors have been demonstrated in the vascular bed, where their stimulation is associated with increased blood flow in the renal, mesenteric, coronary and cerebral vessels (Goldberg, 1974); in the kidney, where natriuresis is stimulated (Goldberg, 1974); and in the pituitary gland, where prolactin secretion is suppressed (MacLeod, 1976). Moreover, in vivo studies suggest that dopamine may be involved in the regulation of growth hormone (Martin, 1976), luteinising hormone (Leblanc et al., 1976), and insulin and glucagon (Leblanc et al., 1977) release.

As far as the gastrointestinal tract is concerned, dopamine is found in raised amounts in gastro-

1Address for reprint requests: Dr Roberto Caldara, 2nd Department of Medicine, Fatebenefratelli Hospital, 23 Corso di Porta Nuova, 20121 Milan, Italy.

Received for publication 14 February 1978 intestinal mucosa, especially in the stomach (Hàkanson et al., 1970), and in the pancreas (Cegrell, 1967). Specific dopamine receptors have been identified in the exocrine pancreas (Hashimoto et al., 1971; Bastie et al., 1977), in oesophageal (De Carle and Christensen, 1976; Rattan and Goyal, 1976), and possibly gastric (Valenzuela, 1976) smooth muscle. Little is known of the effects of dopamine on gastric and pancreatic secretions. Dopamine infusion has been reported to reduce submaximal pentagastrinstimulated acid secretion in the dog (Valenzuela and Grossman, 1976), but not in the cat (Hirst et al., 1976). Pancreatic secretion was increased by dopamine administration in the dog (Hashimoto et al., 1971; Valenzuela and Grossman, 1976; Bastie et al., 1977).

The aim of the present study was to evaluate in healthy man the effects of dopamine infusion on: (1) basal and pentagastrin-stimulated gastric acid secretion, (2) basal and meal-stimulated gastrin release, and (3) basal and secretin-CCK-PZstimulated pancreatic secretion.

\section{Methods}

SUBJECTS

Twenty-four healthy, non-obese subjects who had no history of gastrointestinal disease, volunteered for this study. There were 15 women and nine men aged 35-65 years (mean, 46 years). Informed consent was obtained from all subjects and the research was car- 
ried out according to the Declaration of Helsinki.

GASTRIC ACID SECRETION

This was evaluated in 20 subjects. After an overnight fast a nasogastric tube was passed into the stomach and its position was checked by fluoroscopy. Gastric juice was collected by continuous aspiration, and pooled in 15 minute fractions.

In a group of 10 subjects basal gastric acid secretion was evaluated for 150 minutes after the first 45 minute portion had been discarded; dopamine (Simes Laboratories, Milan, Italy) was infused intravenously at the rate of $4 \mu \mathrm{g} / \mathrm{kg}$-min during one hour from 60 to 120 minutes. Four of these subjects had been pretreated with the antidopaminergic drug, metoclopramide (10 mg intramuscularly), $15 \mathrm{~min}$ utes before the beginning of dopamine infusion.

In the other 10 subjects, after a 30 minute basal period, pentagastrin (Peptavlon, ICI) was infused intravenously at the rate of $1.5 \mu \mathrm{g} / \mathrm{kg}$-h for 150 minutes; dopamine was also infused ( $4 \mu \mathrm{g} / \mathrm{kg}$-min) for one hour from 60 to 120 minutes. Metoclopramide (10 mg intramuscularly) had been administered in four subjects 15 minutes before the beginning of dopamine infusion.

\section{GASTRIN SECRETION}

Serum gastrin concentration was determined at 15 minute intervals before and during dopamine infusion in the six subjects in whom basal gastric acid secretion was evaluated without metoclopramide pretreatment.

The serum gastrin response to a mixed meal was determined in six subjects on two occasions at three day intervals: either normal saline or dopamine (4 $\mu \mathrm{g} / \mathrm{kg}$-min) was infused intravenously in randomised order for one hour beginning immediately before eating. The meal was consumed in 15 minutes and consisted of pasta, bread, beef, potatoes, butter, oil, and $400 \mathrm{ml}$ water (protein $60 \mathrm{~g}$, fat $30 \mathrm{~g}$, carbohydrates $100 \mathrm{~g}$ ).

\section{PANCREATIC SECRETION}

Ten subjects had been studied. After an overnight fast a double-lumen Dreiling tube was passed and positioned under fluoroscopic control with the tip near to the ligament of Treitz. Duodenal aspirate was collected continuously, and pooled in 10 minute fractions.

In five subjects basal amylase and bicarbonate secretion was evaluated for 80 minutes after the first 20 minute portion had been discarded; dopamine (4 $\mu \mathrm{g} / \mathrm{kg}$-min) was infused intravenously for $\mathbf{4 0}$ minutes from 40 to 80 minutes.

In the other five subjects, after a 20 minute basal period, pancreatic secretion was evaluated during a
80 minute simultaneous intravenous infusion of secretin (0.7 clinical units/kg-h) and CCK-PZ (0.7 Ivy units/kg-h) (GIH Laboratory, Karolinska Institutet, Stockholm, Sweden); dopamine $(4 \mu \mathrm{g} / \mathrm{kg}$ min) was also infused for $\mathbf{4 0}$ minutes from $\mathbf{4 0}$ to 80 minutes.

\section{LABORATORY METHODS}

Gastric acid concentration was measured by titration with $0 \cdot 1 \mathrm{M} \mathrm{NaOH}$ to $\mathrm{pH} 7 \cdot 0$ using a semiautomatic titrameter.

Serum gastrin concentration was determined by a modification of the radioimmunoassay technique of Yalow and Berson (1970). Antibodies to gastrin were produced by immunisation of rabbits with synthetic human gastrin I. These antibodies detect little (G-17) and big (G-34) gastrin. The label was monoiodinated 125I-SHG I which had been prepared by the technique of Stadil and Rehfeld (1972). The samples from each subject were run in the same assay and determined in triplicate.

Bicarbonate concentration in the pancreatic juice was measured by adding $0.5 \mathrm{ml}$ duodenal aspirate to $1.0 \mathrm{ml} 0.1 \mathrm{M} \mathrm{HCl}$, boiling and back-titrating the residual $\mathrm{HCl}$ with $0 \cdot 1 \mathrm{M} \mathrm{NaOH}$. Amylase activity was determined by the automatic method of Bourse et al. (1970).

Values were expressed as mean \pm SE. Statistical analysis was performed by the two-tailed, paired Student's $t$ test by comparing the gastric secretion as estimated in 30 minute periods and the pancreatic secretion in $\mathbf{2 0}$ minute periods before, during, and after dopamine infusion.

\section{Results}

No side effects were reported by any subject.

Dopamine infusion was associated with a significant decrease in basal and pentagastrin-stimulated gastric juice volume and acid output. After the end of dopamine infusion the above mentioned measurements rapidly and significantly returned to the preinfusion rates. Pretreatment with metoclopramide abolished all these effects (Figs 1 and 2). Serum gastrin concentration was not affected by dopamine infusion, either in basal conditions or after meal (Figs 1 and 3).

The volume of pancreatic juice was not modified, while amylase and bicarbonate outputs were reduced, though not significantly, during dopamine infusion, both in basal conditions and after stimulation (Figs 4 and 5).

\section{Discussion}

The experimental procedures used to evaluate dopa- 


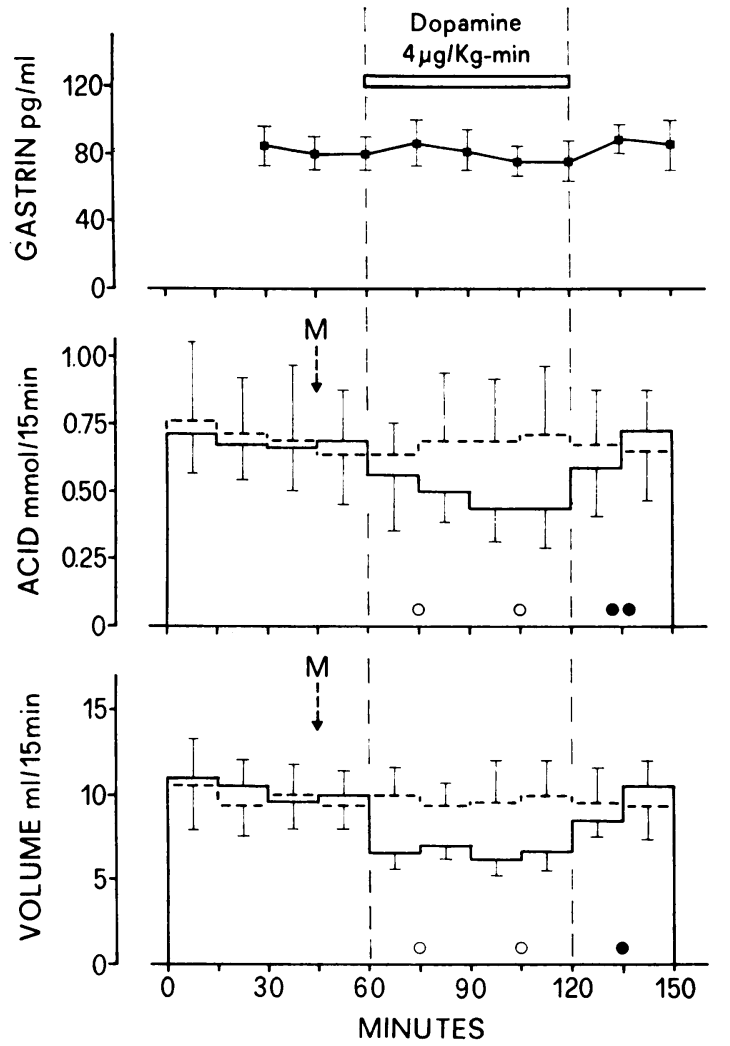

Fig. 1 Mean $\pm S E$ values of basal serum gastrin concentration, gastric acid output and gastric juice volume before, during and after dopamine infusion alone $(-, N=6)$, and after metoclopramide $(M)$ pretreatment $(---, N=4)$. Significant differences were found only in subjects not given metoclopramide (O: 30 minute infusion periods versus 30-60 minute preinfusion period; 0 : 30 minute postinfusion period versus 90-120 minute infusion period). One circle: $\mathbf{P}<0.05$. Two circles: $\mathbf{P}<0.02$.

mine effects on gastric and pancreatic secretions were based on previous works demonstrating that the recovery of basal gastric juice is constant after 45 minute aspiration (Christensen and Stadil, 1976), that the gastric acid secretion reaches a constant rate after 15 minute pentagastrin infusion, and is maintained for two more hours (Rowlands et al., 1969) and that pancreatic secretion achieves constant levels after 20 minute continuous hormonal stimulation (Tympner et al., 1974).

The present study shows that dopamine infusion at the dose of $4 \mu \mathrm{g} / \mathrm{kg}$-min for one hour significantly lowers basal and pentagastrin-stimulated gastric acid secretion, effects which were abolished by pretreatment with metoclopramide, a relatively specific

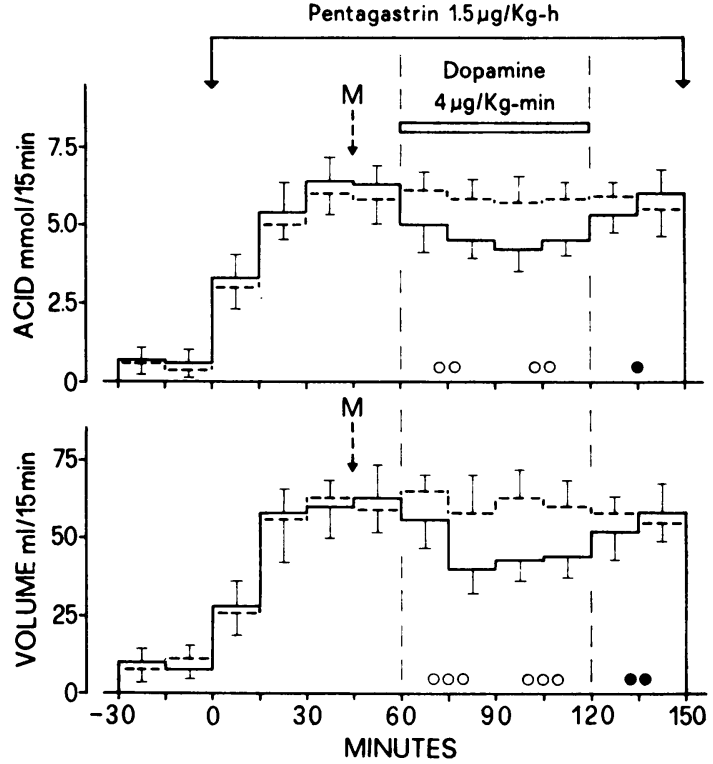

Fig. 2 Mean $\pm S E$ values of pentagastrin-stimulated gastric acid output and gastric juice volume before, during, and after dopamine infusion alone $(-, N=6)$, and after metoclopramide $(M)$ pretreatment $(---$, $N=4)$. Significant differences were found only in subjects not given metoclopramide and are indicated as in Fig. 1 (one circle: $\mathrm{P}<0.05$; two circles: $\mathrm{P}<0.02$; three circles: $\mathrm{P}<0.01$ ).

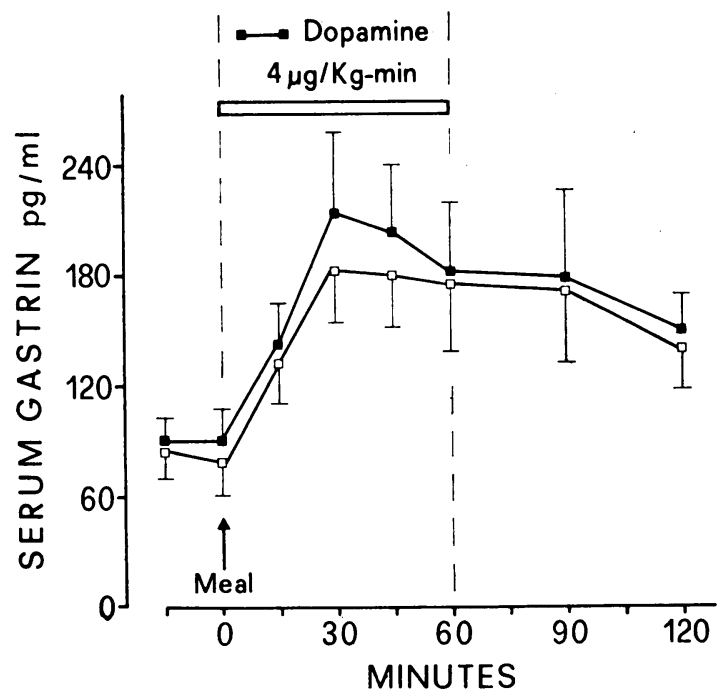

Fig. 3 Mean $\pm S E$ values of meal-induced serum gastrin concentration during dopamine $(\square)$ or saline $(\square)$ infusion in six healthy volunteers. 


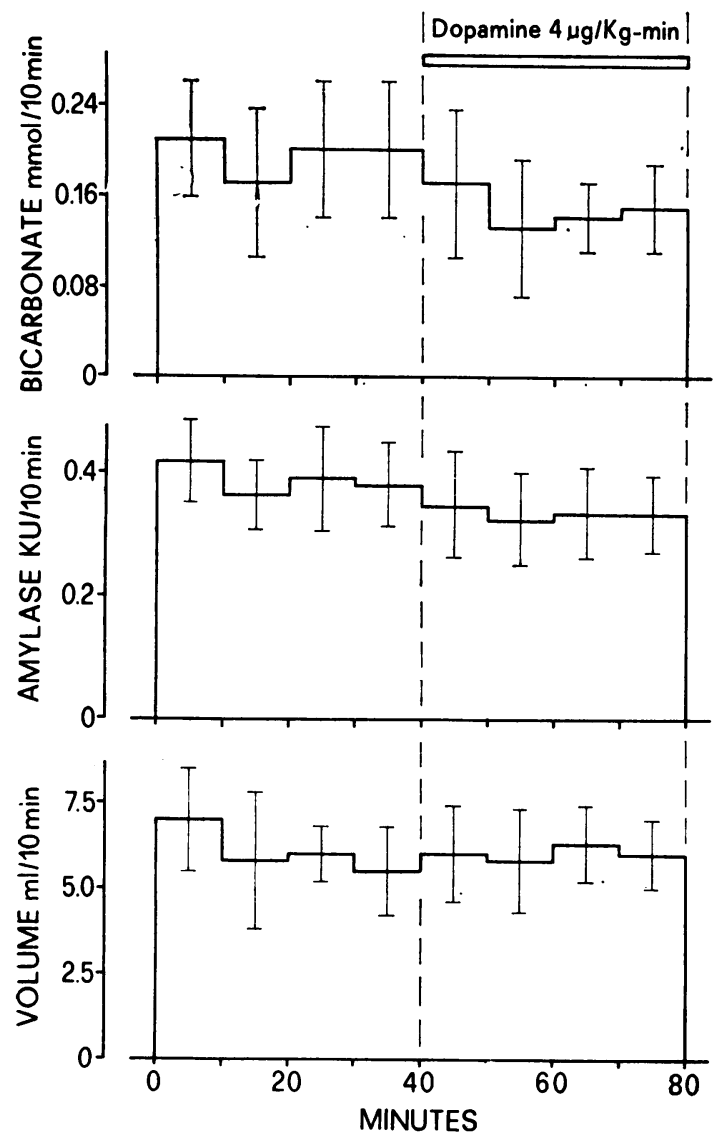

Fig. 4 Mean $\pm S E$ values of basal bicarbonate and amylase outputs and pancreatic iuice volume before and during dopamine infusion in five healthy volunteers.

dopamine receptor antagonist (Peringer et al., 1975). Basal and meal-stimulated gastrin secretion as well as pancreatic flow and bicarbonate and amylase output were not significantly affected.

The reduced gastric acid response to pentagastrin found in humans agrees well with a previous study in the dog (Valenzuela and Grossman, 1976). The smaller inhibition of gastric acid output observed in our experiment might be related to the lower dose of dopamine infused $(4 \mu \mathrm{g} / \mathrm{kg}$-min instead of $10 \mu \mathrm{g} / \mathrm{kg}$ $\mathrm{min}$ ) and/or to the higher administered dose of pentagastrin $(1.5 \mu \mathrm{g} / \mathrm{kg}-\mathrm{h}$ instead of $0.5 \mu \mathrm{g} / \mathrm{kg}-\mathrm{h})$. Though the demonstration of dopamine effects in the stomach even at the infusion rate used in our investigation suggests the existence of dopaminergic mechanisms in the regulation of gastric acid secretion, it cannot be excluded that the observed effects may be primarily of pharmacological rather than physiological significance (Christensen et al., 1976).

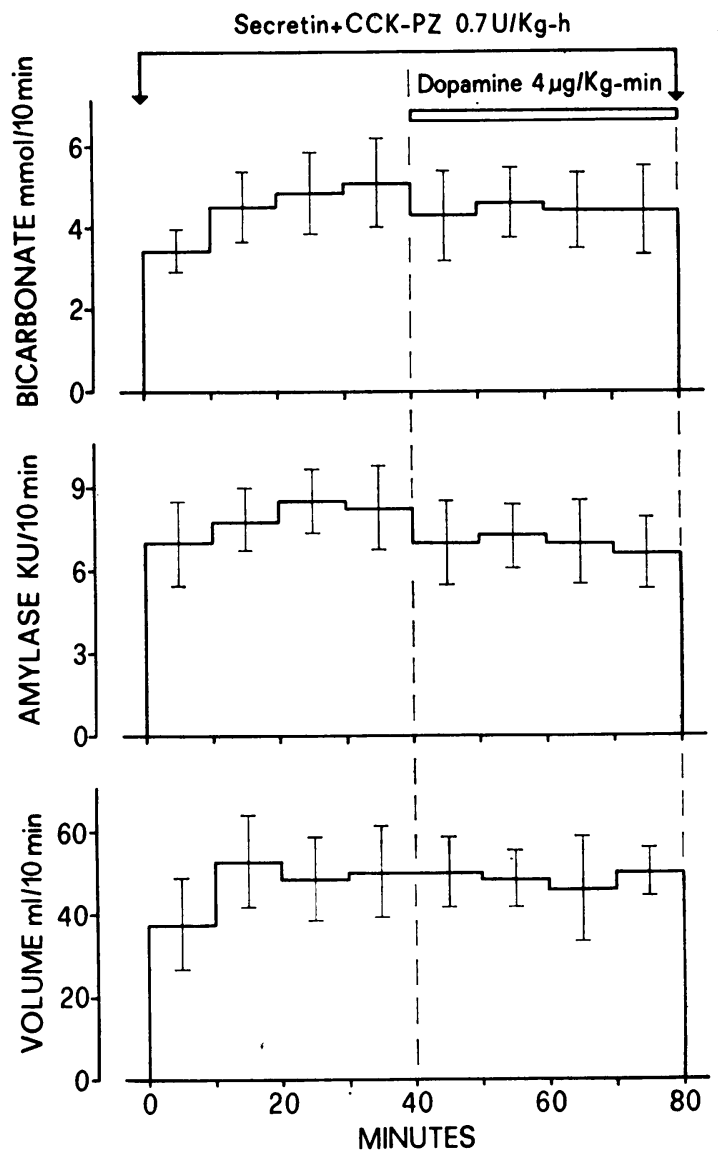

Fig. 5 Mean $\pm S E$ values of secretin-CCK-PZstimulated bicarbonate and amylase outputs and pancreatic juice volume before and during dopamine infusion in five healthy volunteers.

The abolition of these dopamine effects by metoclopramide pretreatment strongly suggests that dopamine inhibition of gastric acid secretion is mediated by stimulation of dopaminergic receptors. However, further studies with drugs acting on adrenergic receptors are needed fully to elucidate the mechanism of dopamine-induced inhibition of gastric acid secretion, as noradrenaline infusion at the dose of $50 \mathrm{ng} / \mathrm{kg}$-min has also been reported to reduce basal gastric acid secretion without modifying gastrin release (Christensen and Stadil, 1976).

As dopamine crosses the blood-brain barrier very poorly (Oldendorf, 1971) the observed dopamine effects are most probably due to actions directly exerted at the gastric level. Gastrin secretion, however, does not seem to be influenced by dopaminergic mechanisms, since dopamine infusion and the 
administration of the dopamine agonist, bromocriptine, do not modify basal (Caldara et al., 1977) and meal-stimulated gastrin concentration (unpublished data).

As far as the effects of dopamine on pancreatic secretion are concerned, our data in humans are at variance with previous works in the dog demonstrating that dopamine significantly increases pancreatic flow, bicarbonate and protein output when infused intravenously in intact animals at the dose of $4 \mu \mathrm{g} / \mathrm{kg}$ min (Valenzuela and Grossman, 1976) or when injected or infused either intra-arterially or intravenously in perfused pancreas (Hashimoto et al., 1971; Bastie et al., 1977). However, it is to be pointed out that dopamine does not modify the response of canine pancreas to secretin stimulation (Bastie et al., 1977). Further investigations with dose-response studies are needed to evaluate whether the observed difference between the pancreatic response to dopamine in dog and man is species or dose related.

We are indebted to $\mathrm{Mr} \mathrm{C}$. Bragagnolo and to $\mathrm{Mr} \mathrm{L}$. Vezzoni for expert technical assistance, and to Simes Laboratories, Milan, Italy, for the generous supply of dopamine (Revivan).

\section{References}

Bastie, M. J., Vaysse, N., Brenac, B., Pascal, J. P., and Ribet, A. (1977). Effects of catecholamines and their inhibitors on the isolated canine pancreas. II. Dopamine. Gastroenterology, 72, 719-723.

Bourse, R., Vaysse, N., and Augier, D. (1970). Dosage automatique de l'amylase dans le liquide duodénal. Revue de Médecine (Toulouse), 6, 89-94.

Caldara, R., Grimoldi, D., and Ferrari, C. (1977). Bromocriptine, gastric acid output, and gastrin secretion (Letter). Lancet, 1, 902.

Cegrell, L. (1967). Dopamine in the pancreas of albinic and pigmented newborn guinea-pigs. Life Sciences, 6, 24912495.

Christensen, N. J., Mathias, C. J., and Frankel, H. L. (1976). Plasma and urinary dopamine: studies during fasting and exercise and in tetraplegic man. European Journal of Clinical Investigation, 6, 403-409.

Christensen, K. C., and Stadil, F. (1976). Effect of epinephrine and norepinephrine on gastrin release and gastric secretion of acid in man. Scandinavian Journal of Gastroenterology, suppl. 37, 87-92.

De Carle, D. J., and Christensen, J. (1976). A dopamine receptor in esophageal smooth muscle of the opossum. Gastroenterology, 70, 216-219.
Goldberg, L. I. (1974). Dopamine-clinical uses of an endogenous catecholamine. New England Journal of Medicine, 291, 707-710.

Hàkanson, R., Owman, C., Sjöberg, N. O., and Sporrong, B. (1970). Amine mechanisms in enterochromaffin and enterochromaffin-like cells of gastric mucosa in various mammals. Histochemie, 21, 189-220.

Hashimoto, K., Satoh, S., and Takeuchi, O. (1971). Effect of dopamine on pancreatic secretion in the dog. British Journal of Pharmacology, 43, 739-746.

Hirst, B. H., Reed, J. D., Gomez-Pan, A., and Labib, L. A. (1976). Bromocriptine potentiation of gastric acid secretion in cats. Clinical Endocrinology, 5, 723-729.

Leblanc, H., Lachelin, G. C. L., Abu-Fadil, S., and Yen, S. S. C. (1976). Effects of dopamine infusion on pituitary hormone secretion in humans. Journal of Clinical Endocrinology and Metabolism, 43, 668-674.

Leblanc, H., Lachelin, G. C. L., Abu-Fadil, S., and Yen, S. S. C. (1977). Effect of dopamine infusion on insulin and glucagon secretion in man. Journal of Clinical Endocrinology and Metabolism, 44, 196-198.

MacLeod, R. M. (1976). Regulation of prolactin secretion. In Frontiers in Neuroendocrinology, vol. 4, pp. 169-194. Edited by L. Martini and W. F. Ganong. Raven Press: New York.

Martin, J. B. (1976). Brain regulation of growth hormone secretion. In Frontiers in Neuroendocrinology, vol. 4, pp. 129-168. Edited by L. Martini and W. F. Ganong. Raven Press: New York.

Oldendorf, W. H. (1971). Brain uptake of radiolabeled amino acids, amines, and hexoses after arterial injection. American Journal of Physiology, 221, 1629-1639.

Peringer, E., Jenner, P., and Marsden, C. D. (1975). Effect of metoclopramide on turnover of brain dopamine, noradrenaline and 5-hydroxytryptamine. Journal of Pharmacy and Pharmacology, 27, 442-444.

Rattan, S., and Goyal, R. K. (1976). Effect of dopamine on the esophageal smooth muscle in vivo. Gastroenterology, 70, 377-381.

Rowlands, C., Temperley, J. M., and Wyllie, J. H. (1969). Pentagastrin-infusion test after atropine or vagotomy. Lancet, 2, 348-349.

Stadil, F., and Rehfeld, J. F. (1972). Preparation of ${ }^{128}{ }^{1-}$ labelled synthetic human gastrin I for radioimmunoanalysis. Scandinavian Journal of Laboratory Investigation, 30, 361-368.

Thorner, M. O. (1975). Dopamine is an important neurotransmitter in the autonomic nervous system. Lancet, 1, 662-665.

Tympner, F., Domschke, S., Domschke, W., Classen, M., and Demling, L. (1974). Reproducibility of the response to secretin and secretin plus pancreozymin in man. Scandinavian Journal of Gastroenterology, 9, 377-381.

Valenzuela, J. E. (1976). Dopamine as a possible neurotransmitter in gastric relaxation. Gastroenterology, 71, 10191022.

Valenzuela, J. E., and Grossman, M. I. (1976). Dopamine stimulates pancreatic secretion and inhibits gastric secretion in dogs (Abstract). Clinical Research, 24, 292 A.

Yalow, R. S., and Berson, S. A. (1970. Radioimmunoassay of gastrin. Gastroenterology, 58, 1-14. 